\title{
Article
}

\section{Outcomes and Well-being Part 2: A comparative longitudinal study of two models of homecare delivery and their impact upon the older person self- reported subjective well-being. A qualitative follow up study paper}

Gethin-Jones, Stephen

Available at http://clok.uclan.ac.uk/2975/

Gethin-Jones, Stephen (2012) Outcomes and Well-being Part 2: A comparative longitudinal study of two models of homecare delivery and their impact upon the older person self-reported subjective well-being. A qualitative follow up study paper. Working with Older People, 16 (2). pp. 52-61. ISSN 1366-3666

It is advisable to refer to the publisher's version if you intend to cite from the work. http://dx.doi.org/10.1108/13663661211231774

For more information about UCLan's research in this area go to http://www.uclan.ac.uk/researchgroups/ and search for <name of research Group>.

For information about Research generally at UCLan please go to http://www.uclan.ac.uk/research/

All outputs in CLoK are protected by Intellectual Property Rights law, including Copyright law. Copyright, IPR and Moral Rights for the works on this site are retained by the individual authors and/or other copyright owners. Terms and conditions for use of this material are defined in the policies page. 


\section{Outcomes and well-being part 2: a comparative longitudinal study of two models of homecare delivery and their impact upon the older person self-reported subjective well-being. A qualitative follow up study paper}

Stephen Gethin-Jones

Stephen Gethin-Jones is based at the University of Central Lancashire,

Preston, UK.

\begin{abstract}
Purpose - This paper aims to follow up on a previous quantitative research project which established that outcome-focussed care appeared to be associated with an increase in the individuals' subjective well-being. The purpose of this paper is to establish why the intervention enabled this.

Design/methodology/approach - The study utilised a qualitative approach to gather the subjective experience of the individual service users. The sample consisted of 20 service users, who were subject of two semi-structured interviews; one interview at the start of the intervention and one at the six month stage. The data were then analysed under core themes raised by the service user in these interviews. The sample was divided into two, with one group receiving the outcome-focussed model of care and the other group receiving the traditional time focussed care.

Findings - The research established that service users' subjective well-being improved due to the ability of outcome-focussed care to provide consistency, flexibility and most importantly the ability of the service user to form a relationship with the homecare workers providing their care.

Practical implications - This paper will assist professionals to understand why outcome-focus care has a profound impact upon service users' subjective well-being as opposed to the existing task focussed care.

Originality/value - This and the previous paper provide an insight into how different processes and models of intervention impact upon the subjective well-being of socially isolated older people.

Keywords Outcome-focus homecare, Older people, Social care, United Kingdom, Elder care, Home care

Paper type Research paper

Background

The coalition government has published a raft of literature aimed at changing the delivery of social care to older people. The government's documents, A Vision for Adult Social Care: Capable Communities and Active Citizens $(\mathrm{DOH}, 2010)$ and Transparency in Outcomes: A Framework for Quality in Adult Social Care (2011) have both focused on the need for services to be provided that are personalised and focused on the desired outcomes of older
\end{abstract}


people. These documents also focus on the importance of building relationships and enabling older people to participate fully in society. This paper reports on the application of outcome focused care developed by Qureshi et al. (1998) and reviewed by Glendinning et al. (2006). The previous research demonstrated the importance of the method of care delivery for the well-being of the older person and, in a previous paper Gethin-Jones (2012) demonstrated the association between care delivery and the individual subjective wellbeing.

\section{Method}

The data for this qualitative study were gathered via the use of two semi-structured interviews. One interview took place at the start of the intervention and one after six months. Two core themes were then developed from the data gathered during the interview and analysed by using both the core and sub-themes displayed in Table I.

The purpose of the interviews was to examine why the participants felt change had happened in the case of outcome-focused care and also why change had not happened with the traditional model of time/task provision.

\section{Sample}

The sample consisted of $(n=20)$ participants. These participants were drawn equally from those receiving the outcome-focused intervention $(n=10)$ and the established time focussed model of care $(n=10)$. As with the quantitative study all participants were aged over the age of 65 and had been assessed as having care needs that were critical and

Q1 substantial (Fair Access to Care Services, DOH, 2003). All participants were considered to have full capacity and consented to take part in the study.

\section{Gender and age distribution}

The sample $(n=20)$ was distributed as females $(n=13)$ and males $(n=7$; the predominance of females would be expected as the mean age of the sample was 76 years.

\section{Model of care}

The first core theme to be considered in this paper is the model of care. This theme was analysed in an attempt to understand why the outcome-focussed model of care had an impact on the individuals' self-reported subjective well-being and why the existing models of time/task care did not. In order for this to be considered, a re-examination of what is considered to be outcome-focused care is required. This will provide clarification as to what constitutes an outcome. An operational definition of an outcome is provided by the Social Care Institute for Excellence (SCIE) and is the one used within this research:

"Outcome" refers to the impacts or end results of services on a person's life. Outcome-focused services therefore aim to achieve the aspirations, goal and priorities identified by service users in contrast to services whose content and/or forms of delivery are standardised or a solely determined by those who deliver them. Outcomes are by definition individualised, as they depend on priorities and aspirations of individual people (Glendinning et al., 2006).

Interestingly there is no definition of what constitutes time/task care. The definition developed by the author gives an overview of its component parts:

Table I Themes from the interview data

\begin{tabular}{lll} 
Core theme & Model of care & Social interaction \\
\hline Sub-theme & $\begin{array}{ll}\text { Issues raised about outcome-focused care } \\
\text { Issues raised about time/task care }\end{array}$ & $\begin{array}{l}\text { Social isolation relationship } \\
\text { Formal carers }\end{array}$
\end{tabular}


Time and task homecare is the division of assessed care needs into time allocated components,

and is measured by the completion of tasks rather than assessed outcomes.

This longitudinal study was concerned with change over time and in order to measure this change the study focused on the individual participants self-identified concerns at the start and at the end of the research. This measurement element has mainly been explored within the previous paper (Gethin-Jones, 2012) by the use of the MYCAW questionnaire (Paterson et al., 2007). However, this measurement did not explain why the change had occurred for the outcome-focussed group. The interviews were used in order to examine why the participants felt change had happened in the case of outcome-focused care and also why change had not happened with the traditional model of time/task provision. Tables II and III show the main concerns expressed by the participants. Concern 1 is the main concern expressed by the participant and concern 2 is the participants' secondary concern.

The inability to go out was a major concern expressed by both groups of participant. This concern was explored further to see whether the model of care has had any major impact upon promoting and meeting the individual's desire to be able to leave the home. Before this paper examines what has changed, it is worth considering how the participants felt about this concern in the initial interview before the intervention had had the opportunity to impact upon the inability to go out. The first question put to those participants who scored the inability to go out highly in either concern 1 or 2 was:

You have identified that the inability to go out is a major concern of yours, could you tell me a bit more?

The first group of responses to this question were from the outcome-focused group:

It's not that I am so disabled I can't go out, but I couldn't manage it on my own. Before Mabel passed o [neighbour] she would drive me to the newsagents on a Sunday, it would take about an hour, the shops only five minutes in a car. Mabel would support me over the step and guide me around the shop, that's all I need. But never going out, apart from the hospital I haven't left this house for six months.

This interview progressed and the individual identified that he had attempted to go out himself but that this had resulted in a fall. He felt his social worker was too worried for him to go out even with support and he felt cross at her lack of trust in him. The next participant was also in a similar situation:

My eyesight isn't so clever now, it is knowing the different heights of things like steps, and I just need someone to say it's a step now Harold watch yourself. If I had that I would be fine.

These two individuals both benefitted from the outcome-focused care. They were able to bank up time to enable them to go out once a fortnight. Although the two outings a month

Table II Self-identified concern 1

\begin{tabular}{llcc} 
Categories & Descriptors for concern 1 & Outcome-focus & Time/task \\
\hline Category 1 & Inability to go out & 6 & 6 \\
Category 2 & Loneliness & 3 & 4 \\
Category 3 & Inability to care for self or others & 5 & 6 \\
Category 4 & No clear category & 5 & 4
\end{tabular}

Table III Self-identified concern 2

\begin{tabular}{llcc} 
Categories & Descriptors for concerns 1 and 2 & Outcome-focus & Time/task \\
\hline Category 1 & Inability to go out & 10 & 10 \\
Category 2 & Loneliness & 7 & 8 \\
Category 3 & Inability to care for self or others & 7 & 8 \\
Category 4 & No clear category & 5 & 4
\end{tabular}


appear quite limited they had a profound impact upon how they both felt about the concern of not being able to leave the house. This is apparent in their responses to the following question:

When I called to see you last time you expressed your main concern was the inability to go out, you haven't identified this as a major concern this time what has changed?

Both individuals had identified in the second interview differing concerns they stated that they felt this concern had been met by their outings:

Well it is great I get one and a half hours every fortnight. I went to the park last week and the newsagents before that. John is still running it and remembered me which was nice. I felt that I was still part of things when John recognised me it was great.

The second participant also had a similar feeling of connection:

We went to the legion it was great, the barman joked about me having a younger women [Care worker] I had a chat about Man U with him, I feel human again.

This was followed up in further conversation, whereby it was the sense for both individuals that somebody in the wider world actually knew about them and they felt more connected. These highly limited visits provided the two men with a purpose; a reason to get dressed up and provided, a focus that enabled them (as they stated) to get through the mundane existence that age had brought to them. Both of the men stated that if this pilot was to stop they would consider saving enough money to pay for these visits to take place.

Similar findings were also reported by two female participants whose physical frailty made it impossible even with the introduction of quality time to have enough staff hours to allow them to leave the home. These two women chose to use their banked time to sit out in the garden in one case to talk to the care worker and watch the school children play in an adjacent playground. Visits were planned with the care worker to correspond with the children's break time. The other female participants just used the time to sit on her patio and talk with the care worker about her family:

It's not just the chat it is the feeling of air on your face and the way the tea tastes different outside.

The second female participant also made similar remarks about the feeling of fresh air but then commented on watching the children play:

The children are so full of life one cheeky lad shouted got any sweets grandma, the girl [carer] said she will check with school if I can give them some sweets, I am so excited.

Both the responses of the male and the female respondents were similar. It was the idea that there was a connection between them and the wider world; that their existence was recognised and in all the cases a real surprise that people either remembered them or were prepared to interact with them. The most exciting development for the women who lived by the school is that although they asked her not to give sweets, they did get parental consent for her to provide the children with cartons of drink. This was only facilitated by the care worker as the drinks were purchased through the school tuck shop and given out by the participant with a member of the playground staff present (the garden literally adjoined the school playground). However, the ability to deal with a participant's concern about the inability to go has also been met in another, more innovative way by one of the care staff. A neighbour who also had mobility problems was enabled to visit the participant by the use of quality time. The fellow flat resident was wheeled from her flat to the participants flat in order for her to visit the participant for half an hour per week. Again this had a huge impact on the persons concern about the inability to go out. This participant was asked the following question:

I notice from your response that the ability to go out is no longer your main concern what has happened to change this, as you have told me that you haven't been able to get out?

Well Jennie [care worker] explained that it would be impossible to get enough staff to get me out [clinically obese] or even to see my friend Doris. So she said if it's ok with Doris [wheelchair bound] I could bring her to see you. I haven't seen Doris since her stroke, although we talk on the phone. It took a bit of sorting but I see Doris every week, so I don't feel so isolated. 
The data generated from the outcome-focussed group demonstrates that this intervention improved the individuals' sense of well-being around their inability to go out. This was achieved in most cases by actually enabling the individual to get out of the home, go into the garden or receive visits. This was made possible by the fact that the intervention could be individualised to suit each service user's context. Therefore, an underlying mechanism operating here is the ability to micro manage the care package around the service users' context in order to meet the service user desired outcome. This is in stark contrast to the response of the service users receiving the time/task model which will be considered next. The same initial question was asked of the service users receiving the time/task model of care:

You have identified that the inability to go out is a major concern of yours, could you tell be a bit more?

These were some of the responses:

I'm a little unsteady on my feet since I had the stroke; my muscles are weak on one side. I do miss going out. It gets you down after a while just staring at the same four walls.

I use to love going to the coffee mornings at the church I really miss that.

My eyesight isn't so clever now I need some help, but I am fit apart from that. I like being out amongst people, you know just hearing them. I slipped last winter and did my hip, so I need a chair now, the staff say they can't get me into the garden they don't have time.

These concerns were very similar to the initial concerns expressed by the outcome-focus group. However, their responses in the follow up interviews were very different to those of the outcome-focus group:

When I called to see you last time you expressed your main concern was the inability to go out, you haven't identified this as changing?

Well it's not on my care plan, so nothing has changed. I spoke to the social worker after your last visit; she said I would have to fund anything like that myself, and she would arrange it. But she hasn't been back since, and she never responds to my calls. I'm so fed up I need to get out.

This individual was in a similar situation to those individuals in the intervention group in that she could get out of the house if someone could steady her. The social worker was asked about the service user's request, but she stated that the case was now closed and if this was to be followed up the service user would have to make a fresh referral. This inflexibility was also observed with another service user, who stated:

I ask the girls all the time when it is nice could they just help me to sit out for $10 \mathrm{~min}$, but they just say if it's not on their schedule (care plan) they can't do it.

This group of individuals felt they were disengaged from the care they received, and this was acutely felt by those individuals who had no additional visits from family and friends; who expressed that they felt like they were just going through the motions of existence, without any attachment to the world and society around them.

This lack of engagement experienced by the service users receiving the time/task model of care was also evident in another major concern about the model of care which was consistency. This lack of consistency was a major concern to both groups in the initial interviews. However, there was a very different response when the second stage interview took place. None of outcome-focus group expressed the lack of consistency as an issue. In fact they commented on how the consistency of the paid care staff had significantly improved their sense of well-being and satisfaction with the care they had received. They also started to speak about the paid care staff by their first name, which did not occur with the time/task participants. This lack of mentioning of staff by name led to the decision after conducting two follow up interviews to ask the participants; "How would you describe your relationship with your paid carers." Table IV shows the responses from five participants from each group at the second stage interview.

None of the time/task group felt they had a relationship with the care team, which was very different from those receiving outcome-focussed care. Therefore, a casual mechanism that 
"Really good I know all about them and they know about me and my past it's lovely"

"I didn't like it at first, being spoken too by my first name, and all the questions. But I feel I have some companions, not friends, but they know what team I support (football) and they have a crack with me, especially if Man City loses, Dave and Jennie are reds (Manchester United Fans)"

"Good it is the best thing best about this care, you get the same people and you feel you can trust them. They said to me one morning. We are a bit concerned about another lady, we will call back later if that's O.K. I knew they would because I trust them, and I thought that's nice that they worry about us, the other lot didn't"

" well I know that they are not friends, but they feel like really good neighbours"

"It is so different to the previous lot (time/task), I see the same faces regularly and they know my little ways and it good, yes a good relationship I think"
"Well its distant they are like robots, it almost as if I was a machine that needs to be maintained.

"They rush in rush out it's like they are changing the hamsters cage. They never ask me how I am or even give me eye contact"

"Some are better than others, the good ones are good they smile and there is gentleness about them, others you feel they really don't care and it point of getting their names it breaks the ice"

"I don't have a relationship with them, their like the dustmen, you don't know them they just do the work and go"

"What relationship" I couldn't tell you their names" just a job like stacking shelves at Tesco. I make a

is apparent is that of consistency and that this consistency improves the ability of the individuals to form an interactive relationship with those who care for them. The consistency of the care staff was a bi-product of the intervention. This consistency had only been provided as it made it easier for the staff providing the new intervention to be managed. There was no long-term plan to ensure consistency should the project be expanded to the rest of the older peoples provision.

\section{Social interaction}

The main thrust of the responses was about how a visit provided focus for the older person and a reason to feel they had a purpose in life. This feeling of a loss of role or purpose was expressed by the wider group and was especially prevalent in those individuals who had no family contact and were totally dependent upon the paid carers. This theme of a lack of purpose and disconnection from the world was very prevalent. This sense of disconnection and isolation was clearly expressed by one of the participants:

Until my last stroke I had a purpose whether it was the garden, a visit to get the paper. I've been on my own for about ten years and this never bothered me, but now, the total isolation really gets me down.

I can see the world on the TV and through my window, and you realise you have absolutely no point.

This individual was receiving the outcome-focussed intervention and this response was at the initial interview stage. This individual's response was the most pronounced change of any participant. This was the response in answer to the question: "What has changed for you since my last visit?"

I feel I have my life back. John [home care worker] has arranged that when I bank up enough hours he comes round and watches some games with me [football matches] it is only once a month, but every time he visit we chat about the forthcoming match. You have got to be able to focus on something or else you might as well give up. 
The model of intervention appears to have made a difference in this individual's case as it has allowed for a relationship to be developed that has provided a focal point. The main concern expressed initially by this participant was focused around his inability to go out. However, although this was expressed in his follow up interview, it had become a focus of his rehabilitation following his stroke to be able to watch a football match in his local pub with his homecare worker.

This expression of a purpose that was provided by the flexibility of outcome-focussed care was expressed by seven out of the ten participants who received the outcome-focused intervention. The main concerns that were expressed around social isolation and the inability to go out appeared to be addressed to a degree by the outcome-focus model of intervention. This was not apparent in the interviews conducted with those participants receiving the traditional time/task model. Table $V$ encapsulates the general responses of the group receiving outcome-focussed care around the theme of social isolation compared to the responses from the time/task group.

The same set of questions were raised with the participants in the time/task group, The older people being interviewed made constant reference to the fact that the paid carers were either very rushed, disinterested or constantly changing. These three factors impacted upon the older person's ability to form a relationship and this lack of a relationship then also prevented the older person finding a focal purpose to be linked to their paid care visits. and the time/task group

Q2 Question Outcome focus response

"I lie in bed and about 4.30 in the morning; I don't sleep that well at my age. I get excited Joyce is coming I think what am I going to tell her today, I wonder if her latest grandchild has arrived yet. The difference having Joyce has made is huge"

\begin{abstract}
"Jenny is good this new care thing oh it is good. The difference, I have been seeing the four of them for the last month I feel I have my life back. They talk about their family and I talk about mine (even though I never see them) I am really worried because they say it is only temporary. I dread going back to how it was before, that was so hard they just didn't really talk"
\end{abstract}

\section{Time/task response}

It's terrible you know I watched the derby (football) this weekend and its good. I still get excited about the football, but I miss my mates coming round and having a good talk about it. The ladies are nice, but there is different ones everyday, their just not interested in many things and they just rush in. try and talk to them. Some will talk but others are really rude they say "can't you see a person in a rush." I think you wait till the day that no one cares about you and you feel so lonely you wonder if is worth waking up"

I was really looking forward to you coming today. Since your last visit it's the only chance I get to talk. The workers come in without a bye or leave, I've had a terrible bunch this last month they are really rough. One lady smokes all the time. I can't stand smoke. I said to her I don't like smoke. Do you know what she said," what you going to do about it you, don't be a cow." Oh I cried why you would be so rude an old lady like me"
"Billy has been great he is a man u supporter its great talking about the match, especially Cantona! He was the best you know. I have a daughter I see her once a month, it's nice but I miss the pub talk. So l've banked up my time and next week we are going to watch the match in my local. I've not been in it for six years. I can see it through the window, and I think what has my life come to I can't even walk 300 yards'

Do you know it upset me to see the state of my husband's grave it was all overgrown. But Andy (carer) reassured me. He said next time we come he would bring my gardening tools and tidy it. He did you know what a lovely man

I do think what the point is now. I have had my life. You know I stare at Stan's picture (deceased husband) and say what it was all about. I feel like the pigs (used to be a farm worker) when you muck out a pig you don't think what are they thinking. It's the same for the girls (care workers) I'm just a pig to them"

It is just an existence you wake up and realise you might say one or two sentences to another person. You feel like you are a burden to everyone. I think they are thinking hurry up and die 
This paper has focused on developing the key themes from the quantitative paper of social interaction, loneliness and relationships. It has demonstrated that when the two models are examined as to their effectiveness on subjective well-being it is the ability of outcome-focussed care to provide flexibility, consistency and most importantly a focal relationship for those experiencing extreme social isolation. This appears to happen even though the actual interaction time between the individual and the paid carer still represents a small proportion of the older person's week.

\section{Key themes to be developed}

- Thorough evaluation of the cost of outcome-focus care including any savings from the reduced cost of long-term care.

- The need to target more flexible and consistent care packages to older people.

- The need to ensure the most socially isolated receive outcome-focus care to maintain their mental well-being.

\section{Q3 Conclusion}

This paper has focused on the "why" question. It has established that the ability of the outcome-focus care model to provide flexibility to meet the desired outcomes of service users assisted in limiting their sense of social isolation. This flexibility coupled with the consistency of care delivery enabled service users to develop focal relationship with the paid care staff, which in many cases provided the only consistent contact with the world outside of the service users' home.

- The need for consistency in care delivery to enable a focal relationship to develop between the professional carer and the service user.

- Flexibility in care delivery to allow for a wider completion of tasks.

- Prioritizing the delivery of outcome-focused care to the most socially isolated.

The need for consistency in care delivery to enable a focal relationship to develop between the professional carer and the service user.

Flexibility in care delivery to allow for a wider completion of tasks.

Prioritizing the delivery of outcome-focused care to the most socially isolated.

\section{References}

DOH (2010), A Vision for Adult Social Care: Capable Communities and Active Citizens, available at: www.dh.gov.uk/en/Publicationsandstatistics/Publications/PublicationsPolicyAndGuidance/DH_121508 (accessed 12 December 2011).

Gethin-Jones, S. (2012), "Outcomes and well-being: a comparative longitudinal study of two models of homecare delivery and their impact upon the older person self-reported subjective well-being", Working with Older people, Vol. 16 No. 1, pp. 22-30.

Glendinning, C., Clarke, C., Hare, P., Madison, J. and Newbronner, L. (2006), Outcome Focused Services for Older People, Adult Services Knowledge Review 13, Social Care Institute for Excellence, London.

Paterson, C., Thomas, K., Manasse, A., Cook, H. and Pearce, C. (2007), "Measure Yourself Concerns \& Well-Being (MYCAW); an individualised questionnaire for evaluating outcomes in cancer support care that includes complementary therapy", Complementary Therapies in Medicine, Vol. 15, pp. 38-41. 
Qureshi, H., Patmore, C. and Nicolas, E. (1998), "Overview of outcomes of social care for older people and carers", Report, Social Policy Research Unit, University of York, York.

\section{Further reading}

DOH (2011), Transparency in Outcomes: A Framework for Quality in Adult Social Care, available at: www.dh.gov.uk/en/Consultations/Responsestoconsultations/DH_125464 (accessed 12 December 2011).

Corresponding author

Stephen Gethin-Jones can be contacted at: sgethin-jones@uclan.ac.uk 


\section{Author Queries}

JOB NUMBER: 147605

JOURNAL: WWOP

Dear Author

Please address all the numbered queries on this page which are clearly identified on the proof for your convenience.

Thank you for your cooperation

Q1 The reference "DOH (2003)" has been cited in the text but not provided in the reference list. Please check.

Q2 In Table V, the table header "Question" column has no data. Shall I retain as such. Please suggest.

Q3 Please check the list in Conclusion section and Implications for practice, as both the contents are same. 